\title{
Types and Selection Criteria for Various Skin Biopsy Procedures
}

\author{
Divey Manocha, Nidhi Bansal and Ramsay S. Farah \\ SUNY Upstate Medical University, New York,
} USA

\section{Introduction}

The skin biopsy is a simple procedure that can assist with the diagnosis of cutaneous disorders. More errors are made from failing to biopsy promptly than from performing unnecessary biopsies. Properly performed, it may confirm a diagnosis, remove cosmetically unacceptable lesions, and provide definitive treatment for a number of skin conditions. Skin biopsies are unique because the lesion can be visualized, allowing for proper selection of biopsy site and technique. Skin biopsies can be performed with minimal risk in critically ill patients, and a timely skin biopsy may avoid other, more invasive procedures. ${ }^{1}$ Skin biopsies may be performed with shave, punch, excisional or incisional techniques.

There are few absolute contraindications to skin biopsy, but all patients should be made aware that biopsies leave scars. In most cases, a biopsy should be avoided at an infected site, although occasionally ruling out infection may be the indication for the procedure. Inquiry should be made regarding allergies to topical antibiotics, antiseptics, local anesthetics, and to tape. Patients should be asked about bleeding disorders and use of drugs known to interfere with hemostasis (anticoagulants and antiplatelet agents). Generally, lesions with the most advanced inflammatory changes should be chosen; evolutionary changes may take several days and a too-early biopsy may reveal only nonspecific features. 2,3, 5, 6 However for blistering diseases, the earliest lesions reveal the more specific histopathology. Consequently, only the newest vesicles and blisters should be biopsied, usually within 48 hours of their appearance.2,3, 4 Older lesions with secondary changes such as crusts, fissures, erosions, excoriations, and ulcerations should be avoided since the primary pathological process may be obscured. For nonbullous lesions, the biopsy should include maximal lesional skin and minimal normal skin. For lesions between $<4 \mathrm{~mm}$ in diameter, the central region should be biopsied or the entire lesion be excised. For larger lesions, the edge, the thickest portion, or the area with abnormal coloration should be biopsied, because these sites will most likely contain the distinctive pathology. Vesicles should preferably be biopsied intact with adjacent normal-appearing skin, because disruption makes histological interpretation more difficult. Similarly, bullae should be biopsied at their edge, keeping the blister roof attached. If the differential diagnosis is broad, taking biopsy from several sites can minimize sampling error. Important cosmetic areas, such as the face should be approached with caution, and areas with poor healing characteristics should be avoided if other sites are available for biopsy.4, 6 Hypertrophic scarring tends to occur over the deltoid and chest areas, and delayed healing can be a problem over the tibia, especially in diabetic patients or in patients with arterial or venous insufficiency. ${ }^{6}$ The 
incidence of secondary infection in the groin and axillae is high; therefore, these areas should only be biopsied if others are unavailable. ${ }^{3}$

\section{Surgical safety}

Performing skin biopsies places the operator at risk of blood-borne infections. Accordingly, vaccination for hepatitis $B$ is indicated, and universal precautions should be observed by wearing gloves and eye-guards. ${ }^{7}$ Shave and punch biopsies are clean but not sterile procedures so mask, gown and sterile gloves are not necessary. ${ }^{5}$ A mask is recommended for operators or assistants known to be respiratory carriers of Staphylococcus or Streptococcus organisms. Mask, gown, and sterile gloves are indicated for excisions, and are reasonable for any patient at increased risk of infection. ${ }^{5}$ Recapping used needles increases the risk of needle sticks, and should never be attempted. Use of forceps during handling of surgical needles is highly recommended to minimize chances of injury. (Fig. 1) Materials that are contaminated with blood or other body fluids should be disposed appropriately in contaminated-materials plastic bags.

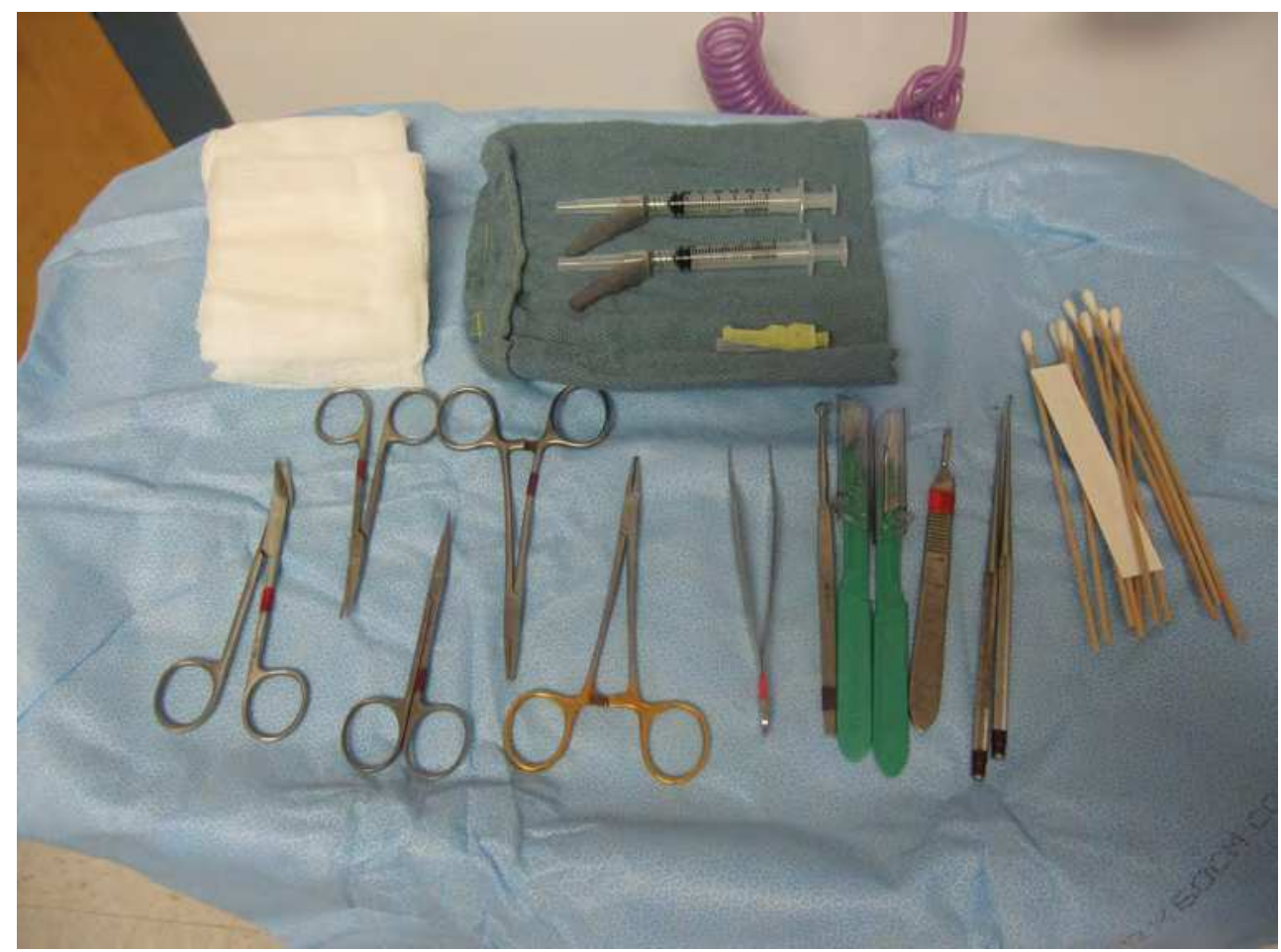

Fig. 1. Instruments used in skin biopsy procedures

\section{Preparing the site}

Common skin antiseptics such as isopropyl alcohol, providone-iodine, or chlorhexidine gluconate can be used to prepare the biopsy site. ${ }^{3}{ }^{5}$ Mark the intended lesion with a 
surgical marker as it may be temporarily obliterated following injection of the anesthetic. (Fig. 2) Marking the outlines for excisional biopsies can be very helpful. For excisions, place a fenestrated surgical drape over the biopsy site after cleansing, but before anesthesia. Round wounds tend to be pulled open in the direction of skin tension lines known as Langer's lines, which are generally parallel to the direction of collagen in the dermis. Tension lines can be demonstrated by gently compressing relaxed skin with the thumb and index finger, and wrinkle lines on the face are another good indicator. Surgical incisions placed parallel to tension lines will close more easily and cosmetically than those placed at right angles. $7,8,9$

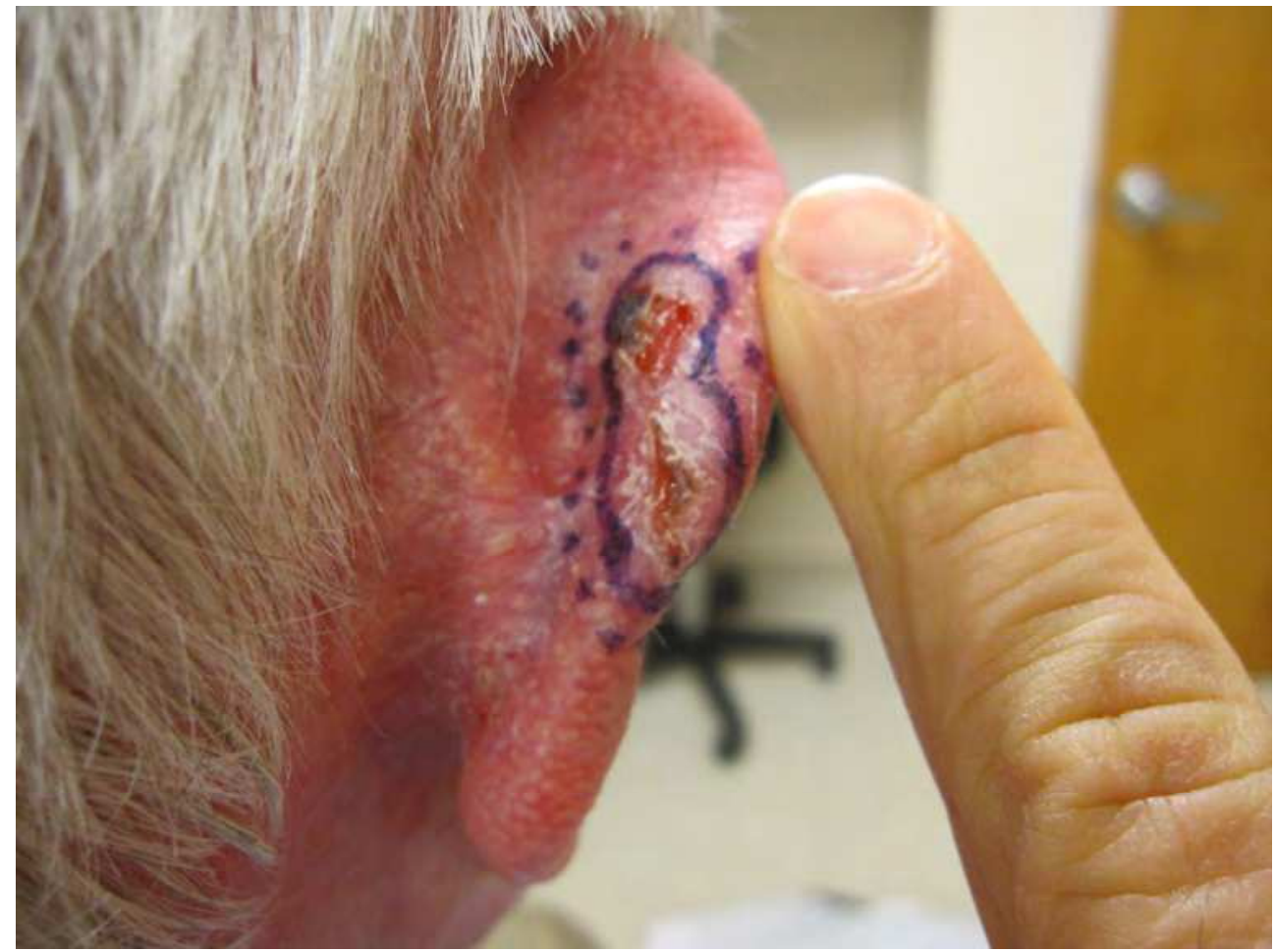

Fig. 2. Lesion on the back of right ear marked for biopsy

\section{Anesthesia}

The most commonly used local anesthetic is $1 \%$ or $2 \%$ lidocaine. Allergy to lidocaine is rare and is often secondary to the preservative. ${ }^{10}$ An allergy to procaine (Novocain) is not a contraindication to the use of lidocaine, since they are chemically different, and cross reaction is rare. ${ }^{11}$ Because lidocaine is a vasodilator, small amounts of epinephrine(1: $100,000)$ are added to constrict blood vessels, provide some degree of hemostasis, prolong anesthesia, and limit lidocaine toxicity. ${ }^{12,13}$ Avoid the use of epinephrine for acral lesions or when large quantities are needed, especially in patients with cardiovascular disease. ${ }^{8,}, 14$ However, epinephrine is absolutely contra indicated in digital and penile blocks because it 
may compromise the blood flow in a confined space. 11,15 The onset of vasoconstriction is slower than that of anesthesia; plan to use this time efficiently by injecting the biopsy site first, then use the subsequent waiting period to select instruments, fill out forms, and explain follow-up care to the patient. (Fig. 3) Adjunctive techniques utilizing topical anesthetics, cryotherapy (ice or liquid nitrogen) or psychologic distraction may compliment routine use of lidocaine. Sterile saline or diphenhydramine (Benadryl) may be substituted in the rare patient allergic to lidocaine. The anesthetic effect of these two agents is primarily attributed to increased turgor pressure. 10,16

The sting of injection can be minimized (presumably by raising the $\mathrm{pH}$ ) by mixing $1 \mathrm{~mL}$ of $\mathrm{NaHCO}_{3}$ with $9 \mathrm{~mL}$ of lidocaine, using a 30-gauge needle, and by making the initial injection perpendicular to the skin. 3, 7, 12 Deep injections sting less than superficial injections, but prolong the time to adequate anesthesia. ${ }^{3}$ Small syringes $(1$ and $3 \mathrm{cc})$ permit easier injection and are less cumbersome to handle. For small lesions the anesthetic can be injected directly into, or immediately adjacent to, the lesion. Some schools of thought recommend not injecting directly into lesions in which a malignancy is being considered highly among the differential diagnoses. This practice protects against the small potential of seeding the area during the procedure. For larger lesions, perform a field block by placing a ring of anesthesia around the surgical site, always advancing and injecting through a site that has been previously anesthetized.7,1

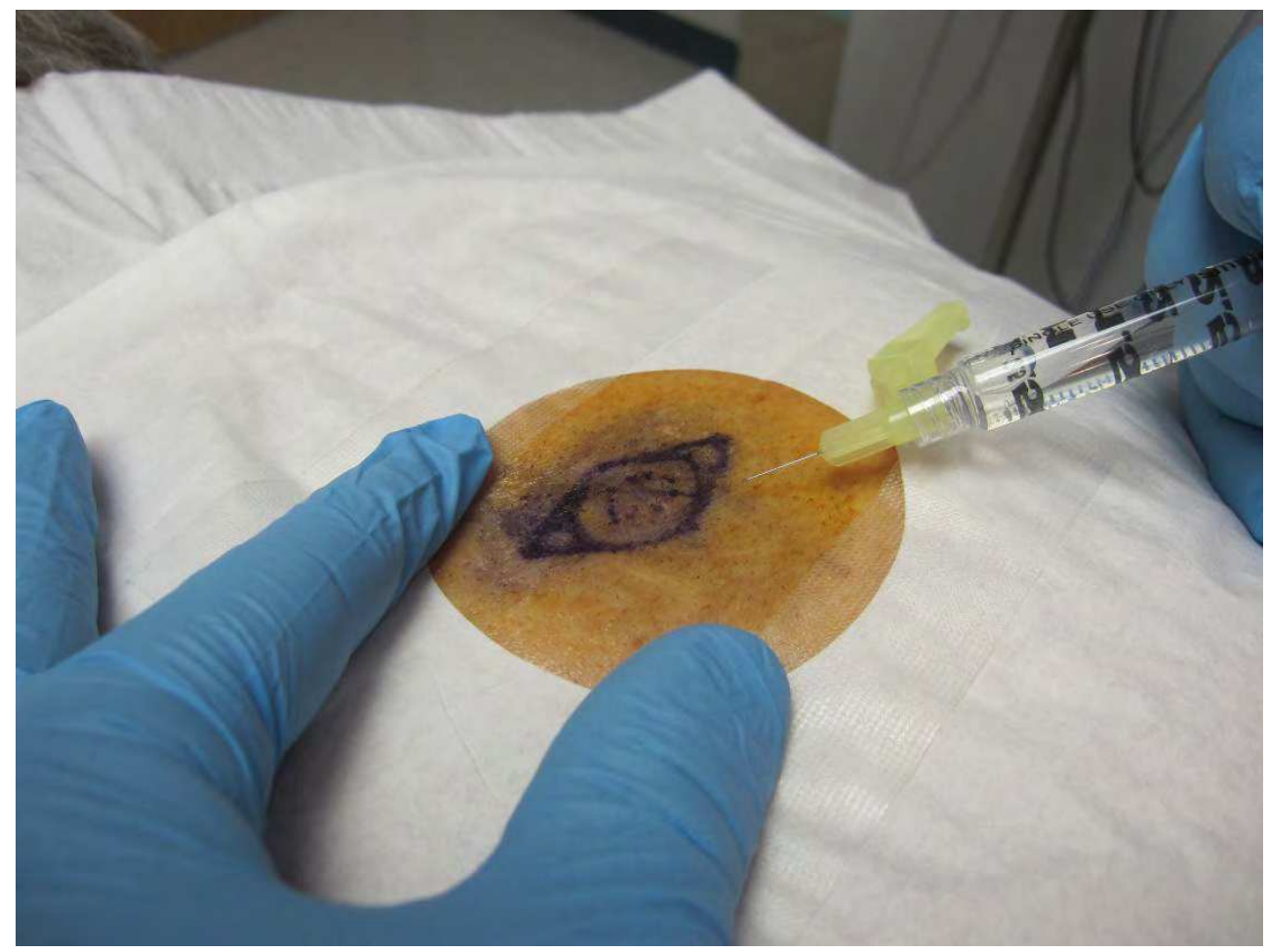

Fig. 3. Administration of local anesthetic agent at the site of skin biopsy 


\begin{tabular}{|c|c|c|}
\hline Technique & Advantages & Disadvantages \\
\hline Shave Biopsy & $\begin{array}{l}\text { - Rapid removal of protruding } \\
\text { portion of superficial, raised or } \\
\text { pedunculated lesions (e.g., milia, } \\
\text { warts, seborrheic keratosis, } \\
\text { molluscum contagiosum, benign- } \\
\text { appearing nevi). }\end{array}$ & 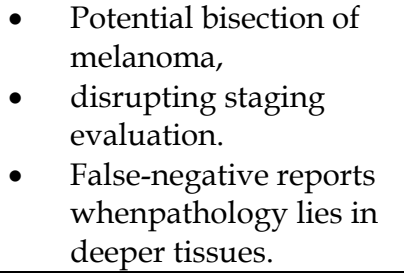 \\
\hline Excisional & $\begin{array}{l}\text { Improved diagnostic sensitivity } \\
\text { for tumors of uncertain diagnosis } \\
\text { or lesions suspicious for } \\
\text { melanoma. Evaluation of deep } \\
\text { pathology in toto removal of } \\
\text { lesions larger than } 6 \text { mm; useful } \\
\text { for multiple studies from a single } \\
\text { biopsy. (e.g., culture, routine } \\
\text { histology, immunofluoroescence). }\end{array}$ & $\begin{array}{l}\text { - Increased time needed } \\
\text { forprocedure. } \\
\text { Occasionally creates a } \\
\text { large skin defect that } \\
\text { necessitates layered } \\
\text { closure with sutures. }\end{array}$ \\
\hline Punch Biopsy & $\begin{array}{ll}\text { - } & \text { Rapid, simple and safe technique } \\
\text { - } & \text { Essy removal of small tumors } \\
& \text { needed for diagnosis of systemic } \\
\text { skin disorders (e.g., } \\
\text { psoriasis,erythema multiforme, } \\
\text { connective tissue disorders, } \\
\text { sarcoidosis and bulous skin } \\
\text { diseases'). }\end{array}$ & $\begin{array}{l}\text { May be inadequate for } \\
\text { diagnosisof melanoma. }\end{array}$ \\
\hline Incisional & $\begin{array}{ll} & \text { Conservative biopsy of deep } \\
\text { subcutaneous disorders (e.g., } \\
\text { panniculitis, fibrous tumors) } \\
\text { - } \quad \begin{array}{l}\text { Diagnosis of large lesions without } \\
\text { in toto removal. }\end{array}\end{array}$ & $\begin{array}{l}\text { May be inadequate for } \\
\text { diagnosisof melanoma. }\end{array}$ \\
\hline
\end{tabular}

Table 1. Comparison of Four Common Biopsy Techniques

\section{Shave biopsy}

Shave biopsies are quick, require little training, and do not require sutures for closure. Lesions that are most suitable for shave biopsies are either elevated above the skin, or have pathology confined to the epidermis. Examples include seborrheic or actinic keratoses, skin tags, warts, and superficial basal or squamous cell carcinomas. Shave biopsies should not be used for pigmented lesions; if an unsuspected melanoma is partially removed, it cannot be properly staged. (Table 1) 5, 12,18

\subsection{Performing a shave biopsy}

Shave biopsies are classified into superficial and deep. Superficial shave biopsies are done across or nearly parallel to the skin surface and extend into the epidermis only or epidermis and limited superficial dermis. The shave biopsy can be facilitated by raising the lesion with 
a wheal of injected anesthetic, allowing the lesion to be propped up and stabilized between the thumb and forefinger. 8,14 To shave a lesion, a number 15 blade is held parallel to the skin surface, and the biopsy is performed by using a smooth sweeping stroke rather than a sawing motion. (Fig. 4) Near the end of the shave maneuver, place the index finger on top of the lesion to stabilize and prevent tearing with the exit of the blade. The depth of the biopsy is controlled by the angle of the blade. Care should be taken to keep the blade parallel to the skin surface, avoiding irregular, deep penetration.

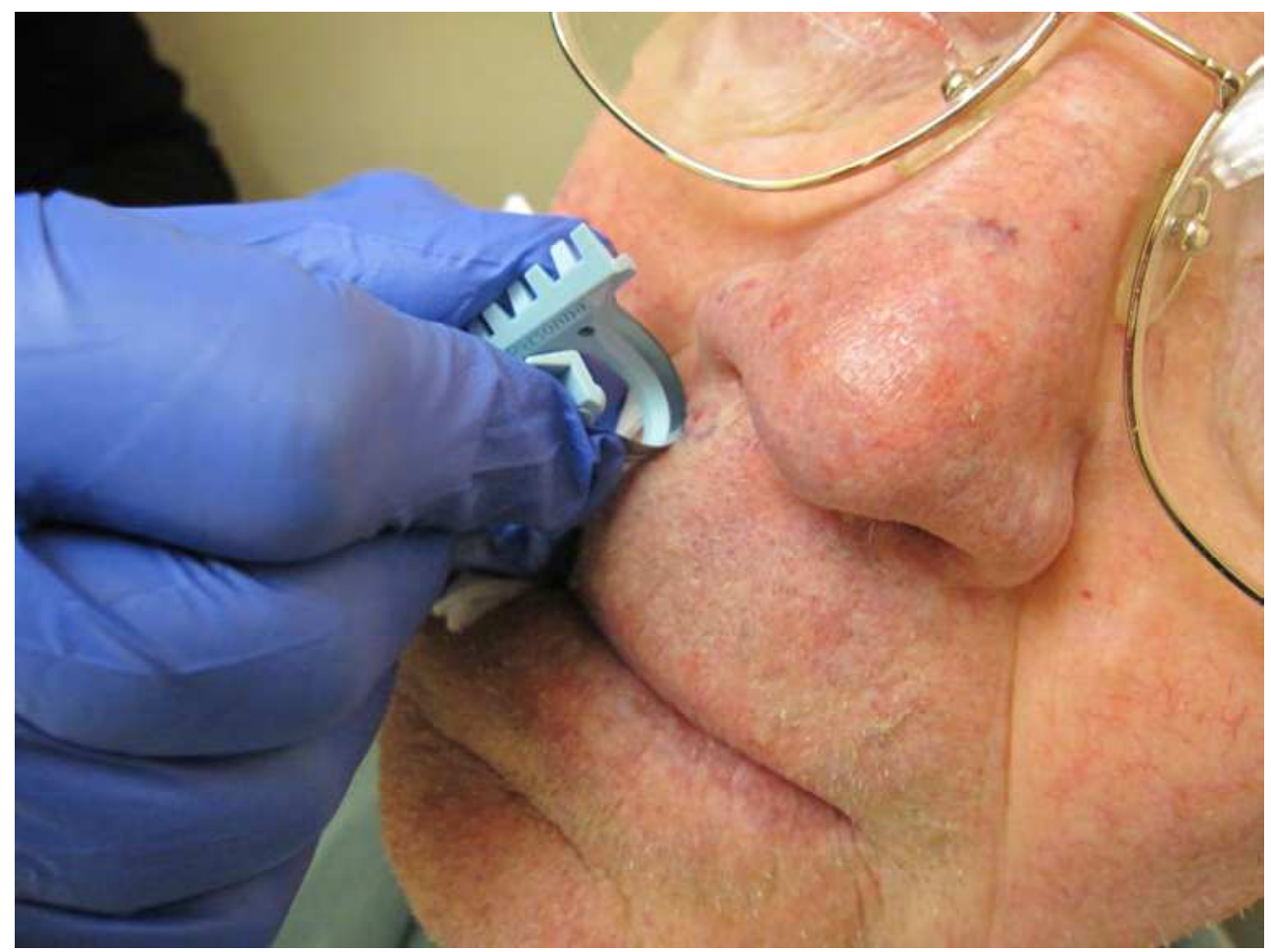

Fig. 4. Performing shave biopsy

A double-edge razor blade cut longitudinally can also be used for shave biopsies. The razor technique has several advantages; it is sharper than most blades, the razor can be bent concave or convex with the thumb and forefinger to better conform to the surface being cut, and width is easily controlled by increasing or decreasing the convexity of the curve. The depth of the shave biopsy can be controlled by varying the angle of contact between razor blade and the skin surface. Curved scissors can be used to perform shave biopsies. Curved scissors are an efficient means of removing skin tags and other small, exophytic growths. ${ }^{12}$ The lesion to be removed is stabilized with toothed forceps, and then cut at the base.

The deeper shave biopsy (also known as "saucerization" biopsy) facilitates sampling of dermis and epidermis which is important for assessing basal cell and squamous cell carcinomas. The scalpel is held like a pen to make a small vertical incision into the skin with 
the beveled tip. The scalpel is then turned and blade is moved forward in a horizontal sawing motion, turning it up towards the surface to finish the excision. ${ }^{19}$ This procedure can also be accomplished with the same amount of ease using a double edged razor blade as an alternative. The defect created is that of a saucer.

\subsection{Hemostasis}

Shave biopsies are quick and do not require sutures for closure. Bleeding following small shave biopsies can often be controlled with pressure alone. Persistent oozing can be stopped with $20 \%$ aluminum chloride in absolute alcohol, which is the most commonly used haemostatic agent. (Fig. 5) It is very efficacious and causes minimum tissue destruction. Other hemostatic agents, in order of increasing corrosiveness, are Monsel's solution (ferric sub sulfate), trichloroacetic acid, and silver nitrate. Although Monsel's solution is more effective than aluminum chloride, it also causes more tissue destruction and, like silver nitrate, can result in skin pigmentation. 3,7

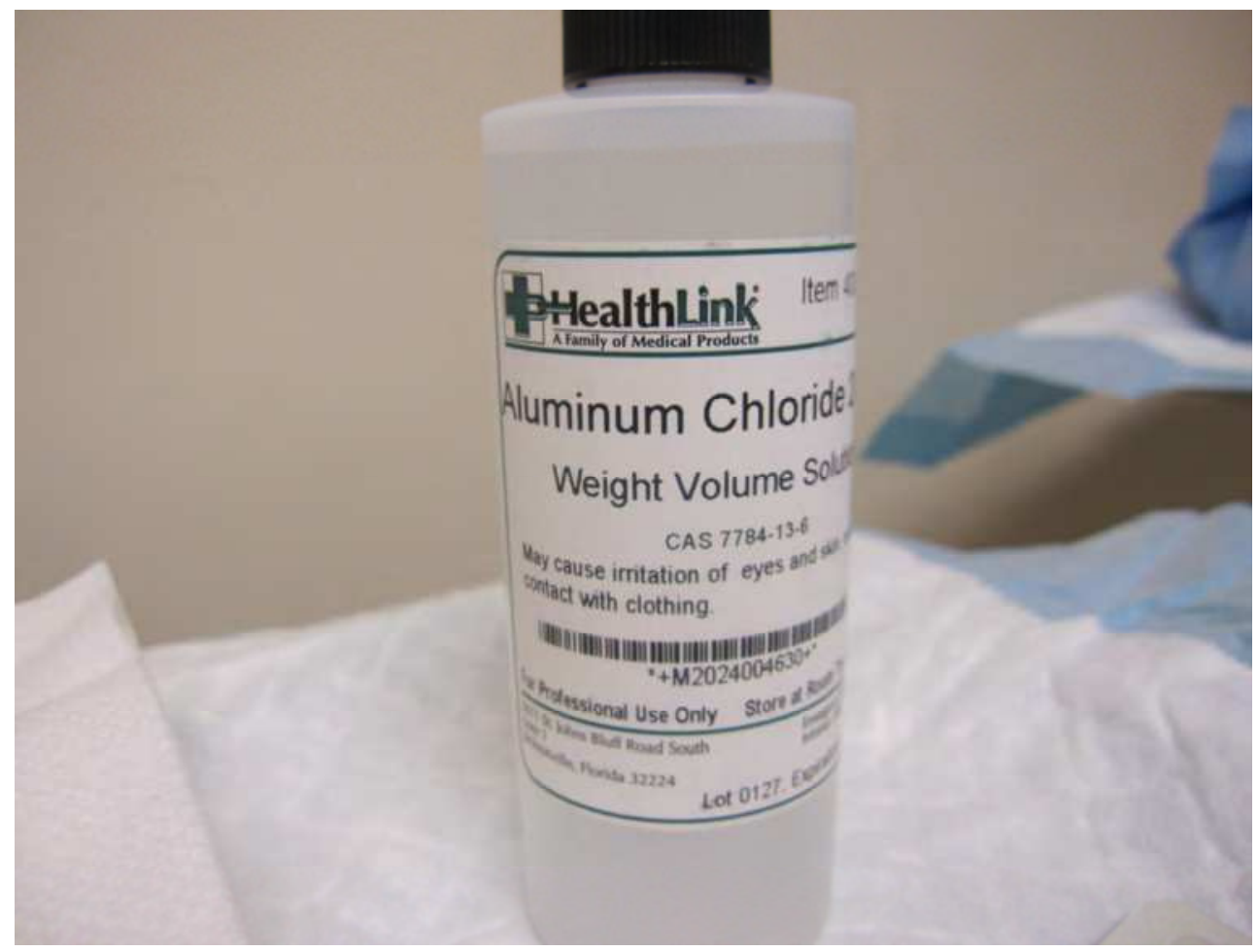

Fig. 5. Aluminum chloride: Most commonly used hemostatic agent

For hemostatic agents to be effective; the wound must be as dry as possible, following which the agent is applied with a cotton applicator using firm pressure with a twisting motion. (Fig. 6) In general, excellent hemostasis following shave biopsies can be achieved in patients with bleeding disorders or in those taking warfarin or aspirin with the combined use of aluminum chloride and several minutes of direct pressure over the wound. 


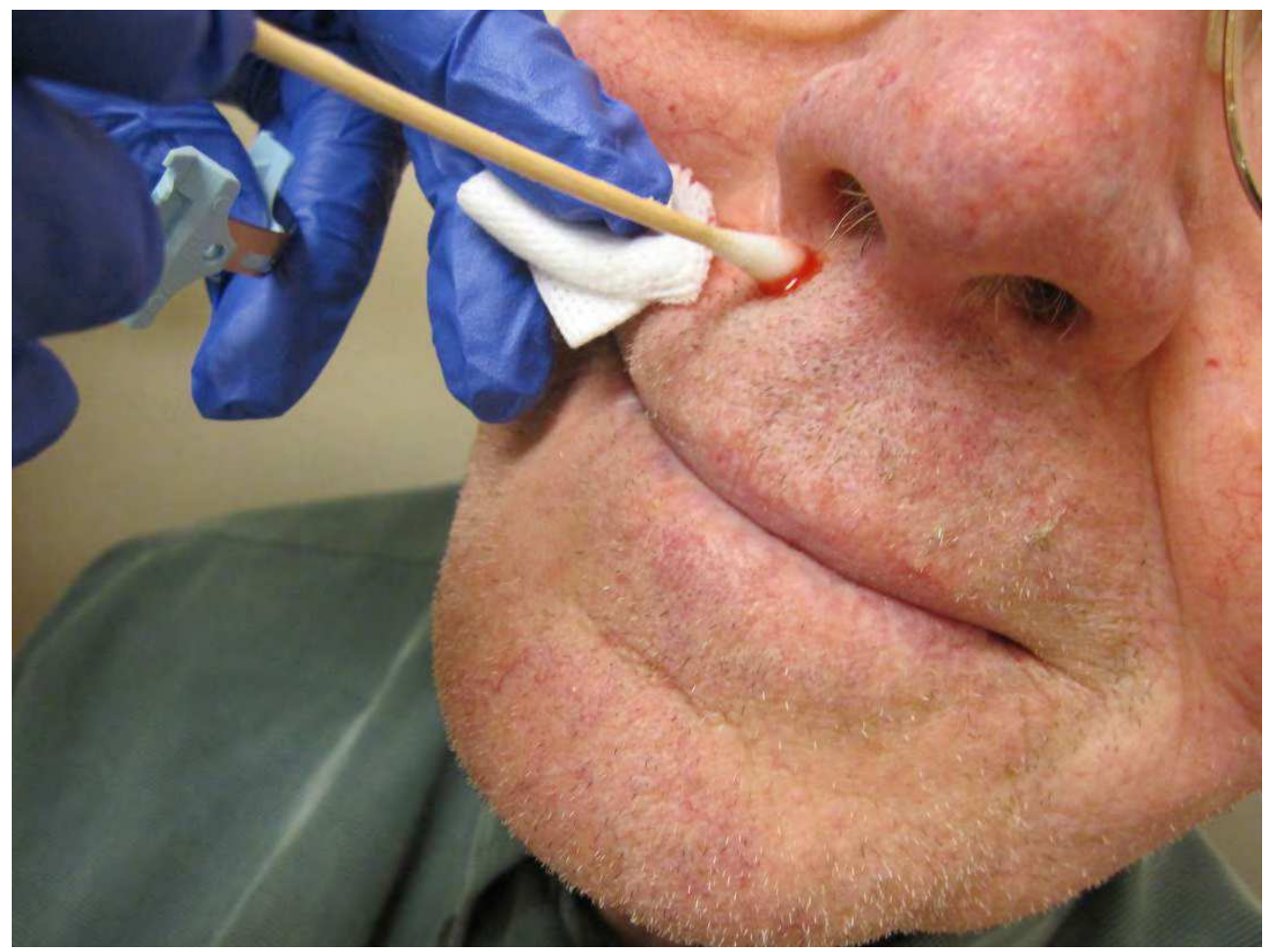

Fig. 6. Application of local haemostatic agent

\section{Punch biopsy}

Punch biopsies are performed with round, disposable knives ranging in diameter from 2 to $10 \mathrm{~mm}$, but $3 \mathrm{~mm}$ is the smallest size likely to give sufficient tissue for consistently accurate histologic diagnosis. ${ }^{20}$ The punch is an ideal procedure for diagnostic skin biopsy or removing small lesions, and often provides a better cosmetic result than a shave biopsy. Punch biopsies can heal by secondary intention, but punches greater than or equal to $3 \mathrm{~mm}$ may produce unacceptable scarring and are best closed with one or two sutures. Punch biopsies are easily mastered by most practitioners, are quick, and have a low incidence of infection, bleeding, nonhealing, or significant scarring. 3,5

Punch biopsies yield a cone shaped core of tissue with its widest diameter at the skin surface and narrowest at the biopsy base. The direction of the skin tension lines at the biopsy site should be determined prior to performing a punch biopsy. The procedure to perform a punch biopsy is as following:

Raise an intradermal wheal with anesthetic agent. Stabilize the skin with the thumb and forefinger, stretching it slightly perpendicular to the normal skin tension lines; this will produce an oval rather than round defect, facilitating closure. (Fig. 7) ${ }^{4}$ Place the punch perpendicular to the skin and apply firm and constant downward pressure with a circular twisting motion. Removal of the punch to "check the progress" should be avoided as this may result in a ragged wound and a shredded biopsy sample. ${ }^{21}$ 


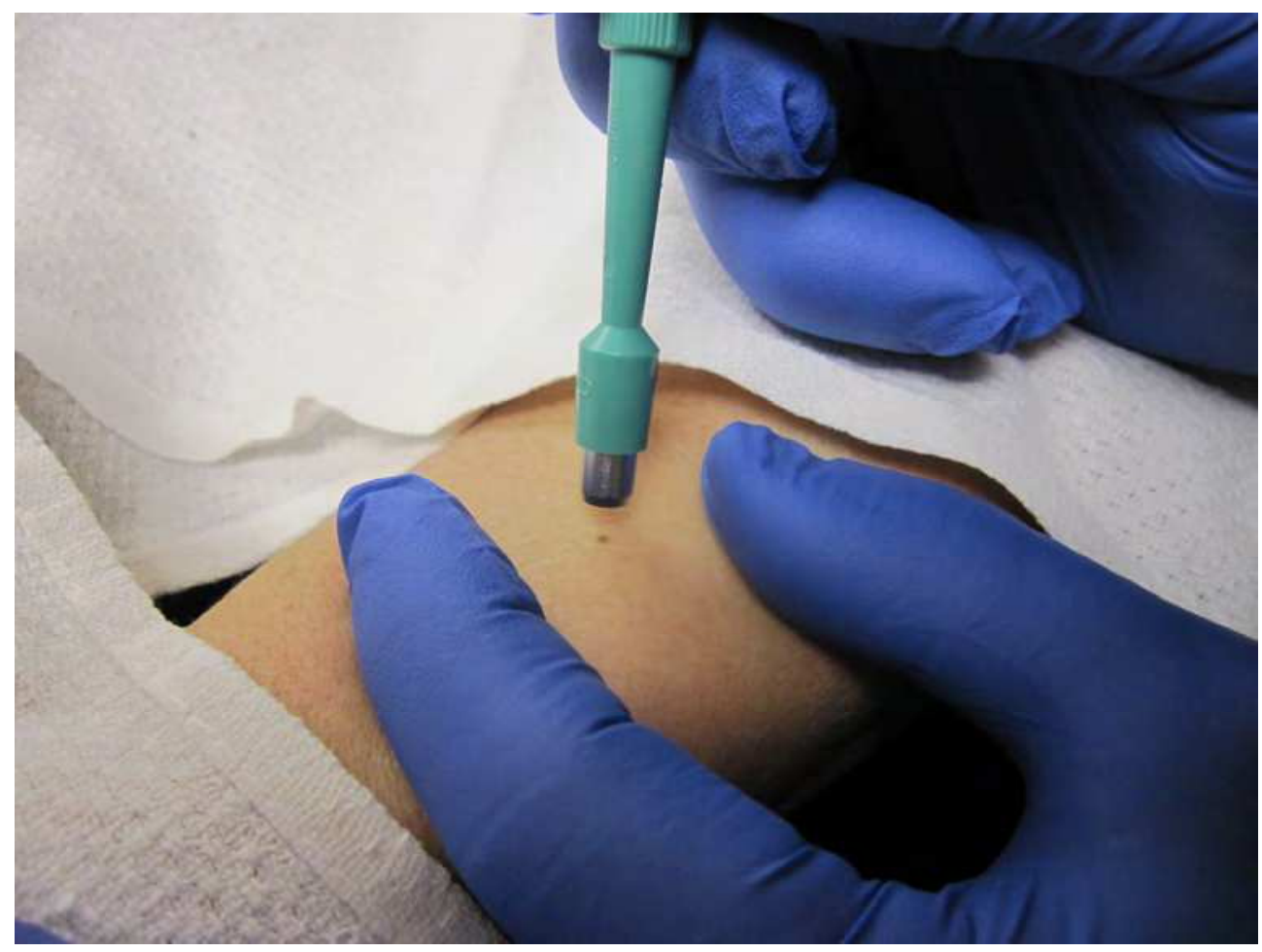

Fig. 7. Performing punch biopsy procedure

A definite "give" occurs when the punch reaches the subcutaneous fat, indicating that a fullthickness cut has been made. Remove the punch and apply downward finger pressure at the sides of the wound to pop up the core. Completely elevate the core with gentle use of forceps or a needle tip and excise it at its base with small tissue scissors. The pressure applied through forceps to elevate the core should be gentle to minimize the destruction and distortion of tissue in the biopsy sample. After finishing the harvest of the tissue, prepare the biopsy site for closure.

Punch biopsies of the scalp for diagnosis of hair disorders are best accomplished using a $4 \mathrm{~mm}$ punch and holding it at $20^{\circ}$ to the surface of the scalp, roughly along the axis of the hair follicle. ${ }^{5}$ Biopsies of scalp lesions suspected of being malignant are performed in the same manner as other punch biopsies, with the punch perpendicular to the skin surface.

Punch biopsies can be closed with one or two sutures or allowed to heal by secondary intention. Wounds that are allowed to heal by secondary intention may be treated with a hemostatic agent such as aluminum chloride or absorbable gelatin. These agents are not needed if sutures are to be used. Contraindications to suturing include biopsies in infected or poorly healing skin; these wounds heal better by secondary intention. The punch is an ideal procedure for diagnostic skin biopsy or removing small lesions. It often provides a better cosmetic result than a shave biopsy. ${ }^{5}$ 


\section{Excisional biopsy}

Excisions are reserved for lesions that cannot be removed with a punch owing to size, depth, or location. Excisions are especially well suited for removal of large skin tumors or inflammatory disorders deep in the skin, involving the panniculus. Excisions require the greatest amount of expertise and time; they almost always require sutures, and are more easily performed with an assistant. ${ }^{3}, 5$ It is strongly recommended that practitioners receive clinical training before attempting an excisional biopsy, or refer patients requiring an excision to a qualified dermatologist or surgeon.

These are performed for lesions that require complete removal for diagnostic or therapeutic purposes. An excisional biopsy allows for histopathologic examination of an entire lesion. Another advantage of an excisional biopsy is the amount of tissue that can be excised, allowing for multiple studies (culture, histopathology, immunofluorescence, electron microscopy) from one biopsy site. ${ }^{5}$ The direction of the skin tension lines should be determined in preparation for an excision. Align the long axis of the excision parallel to the skin tension lines. Using a surgical marking pen, draw an ellipse around the lesion to be excised, including a 2 to $5 \mathrm{~mm}$ margin of normal skin around the lesion, with $30^{\circ}$ angles at each apex, and the length three times the width. (Fig. 8) Holding the scalpel with a number 15 blade like a pen, begin the incision at one apex with the blade perpendicular to the skin. As the incision progresses, use more of the belly of the blade, raising it to the perpendicular again at the next apex. 14

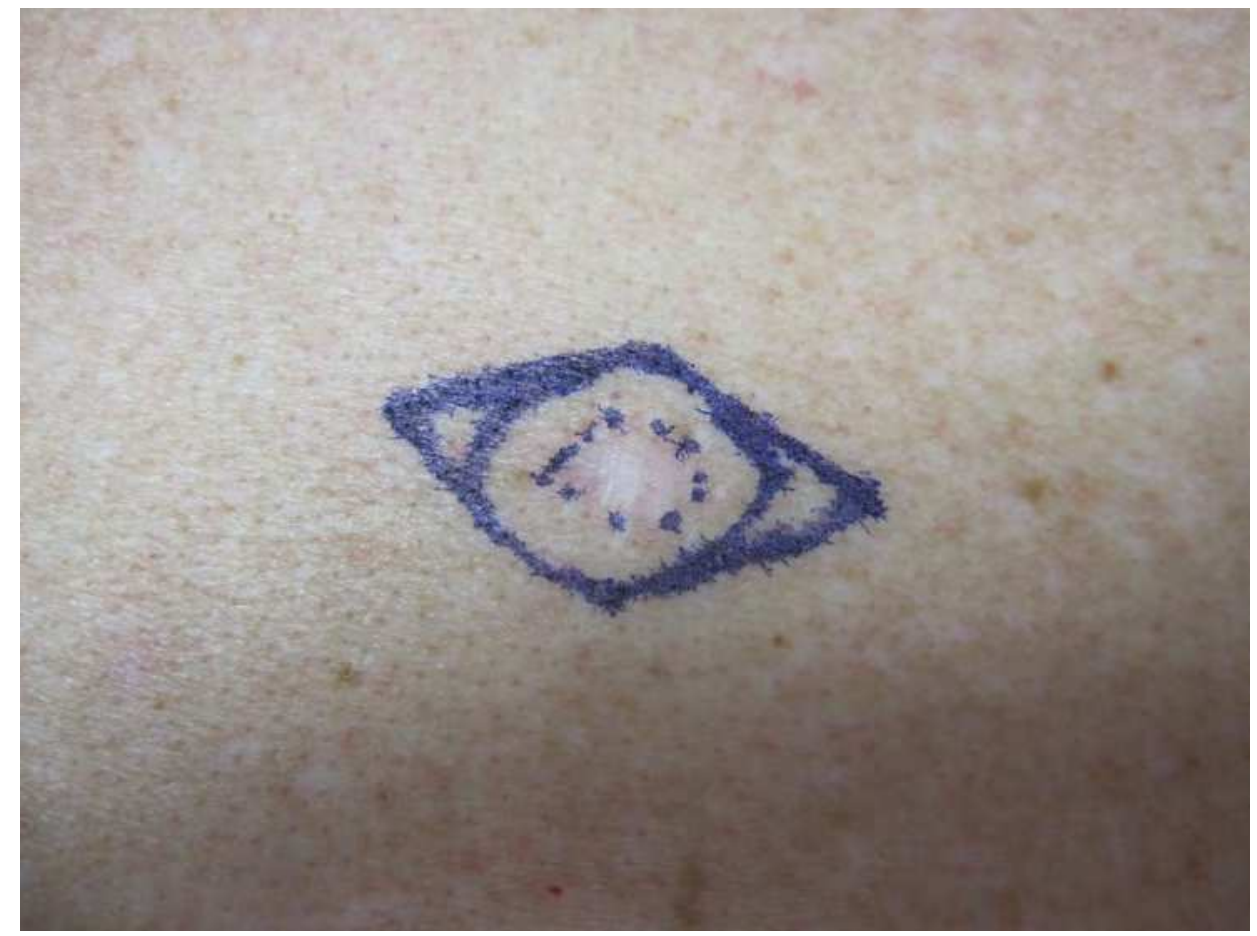

Fig. 8. Lesion marked in elliptical fashion prior to excisional biopsy 
The blade should be angled away from the lesion, slightly undermining the wound edge. This will allow for easier eversion of the wound edge during closure, improving the cosmetic result and decreasing the risk of dehiscence. (Fig. 9) Carefully lift the sample edge with fine forceps once the ellipse has been incised and completely undermine the sample at the level of the subcutaneous fat with scalpel or scissors. Apply pressure to the wound with gauze in preparation for closing.

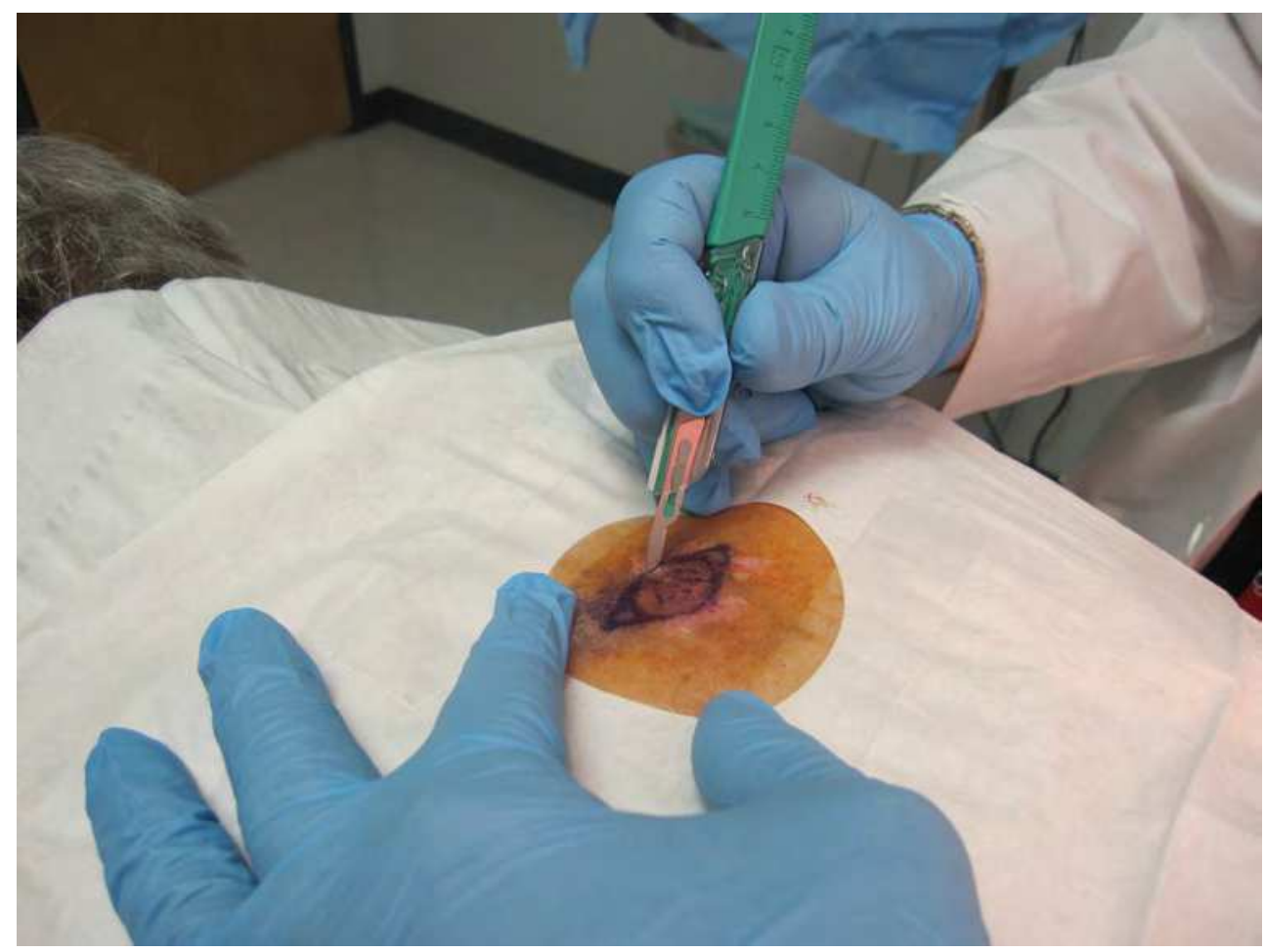

Fig. 9. Performing excisional biopsy

For some physicians, it will be technically easier to perform a diamond-shaped excision for small lesions, and a hexagonal-shaped excision for larger lesions. ${ }^{4}$ The lines of the excision can be marked with a surgical marker prior to anesthesia. For diamond excisions, the blade is inserted vertically into the skin to make the four straight-line incisions of the diamond. For the hexagon, two straight and parallel lines are incised on either side of the lesion and then connected at each end by two more straight incisions to form the hexagon. 4

Excisions require the greatest amount of expertise and time; they almost always require sutures, and are more easily performed with an assistant. ${ }^{5}$

\section{Processing the biopsy sample}

For light microscopy, the specimen should be placed in a $10 \%$ buffered formalin solution provided by pathology; each specimen should be placed into a separate bottle and identified. Specimens less than $1 \mathrm{~cm}$ in greatest dimension can be fixed in $30 \mathrm{~mL}$ of 
formalin, but larger specimens will require more formalin for adequate fixation. (Fig. 10) If a large complicated specimen needs to be sectioned, clue the pathologist to the location of the lesion by sectioning through its center and marking the normal skin borders with surgical marker. Careful attention must be paid to labeling the specimen. Include patient and physician name, date, and location of the lesion. The latter is especially critical if more than one lesion is removed. The specimen label must match the pathology request form and the description in the medical record. On the request form, list the clinical diagnoses and give a short clinical history and description of the lesion or rash.10, 12 Focused clinical history and differential diagnoses are of immense help to the pathologist to arrive at a correct histological diagnosis. If a tumor has been removed, request that the margins be checked for tumor. Whenever possible, the specimen should be submitted to a dermatopathologist. ${ }^{3}$

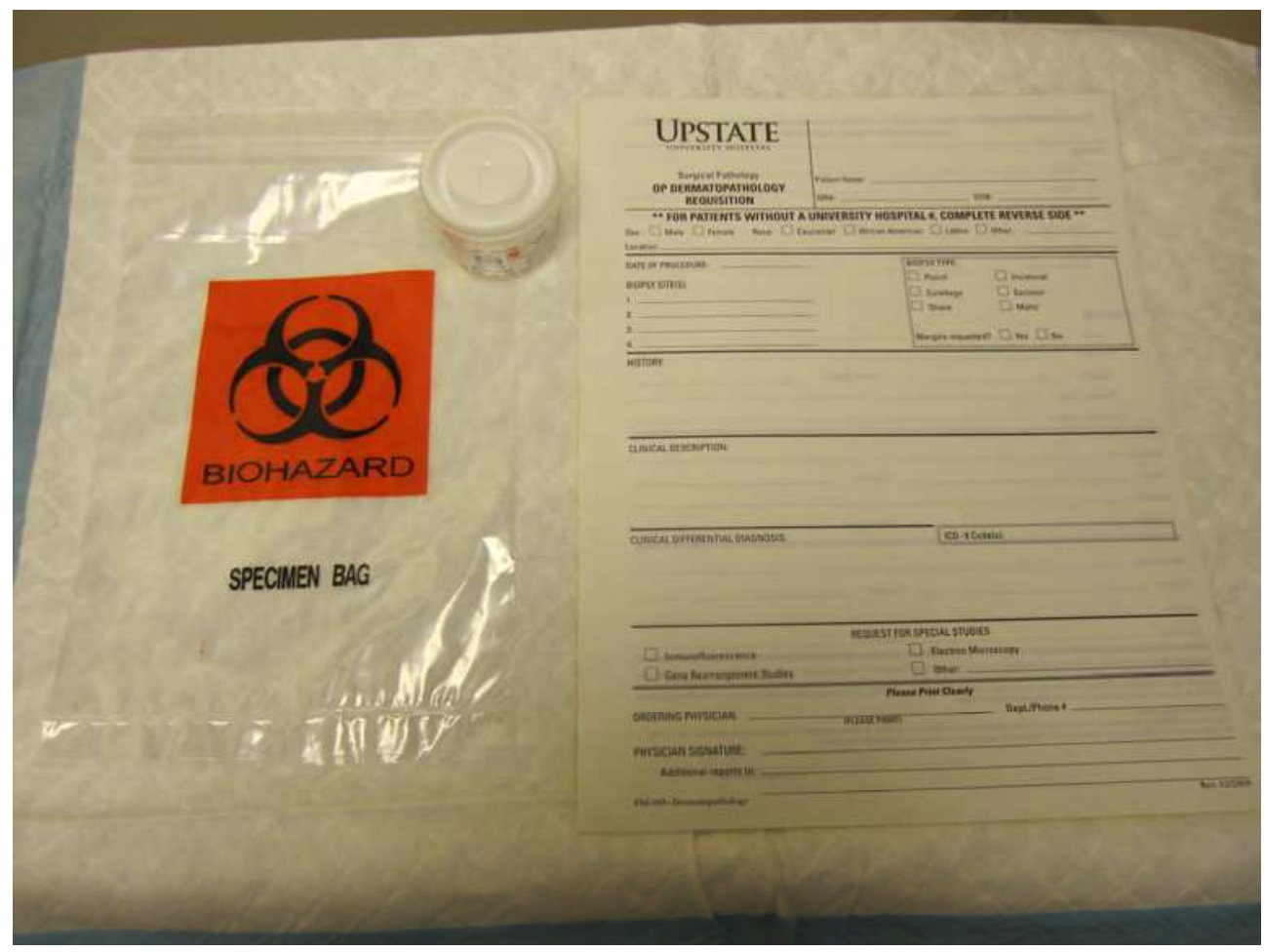

Fig. 10. 10\% buffered formalin solution and Pathology request form

\section{Preparing the wound for suturing}

Prior to closing excisional wounds, the edges of the wound may need to be undermined either sharply with a scalpel or bluntly with scissors. Blunt dissection is performed by advancing the closed scissors under the wound edge, and quickly spreading them open. The width of undermining varies with the size of the wound, but for most wounds, 5 to $10 \mathrm{~mm}$ is sufficient. Undermining allows the skin edges to evert more easily and reduces tension on 
the sutures. (Fig. 11) It is a very useful technique; however care should be taken not to overdo it to minimize tissue destruction, risk of bleeding and post procedure pain. $3,5,16$

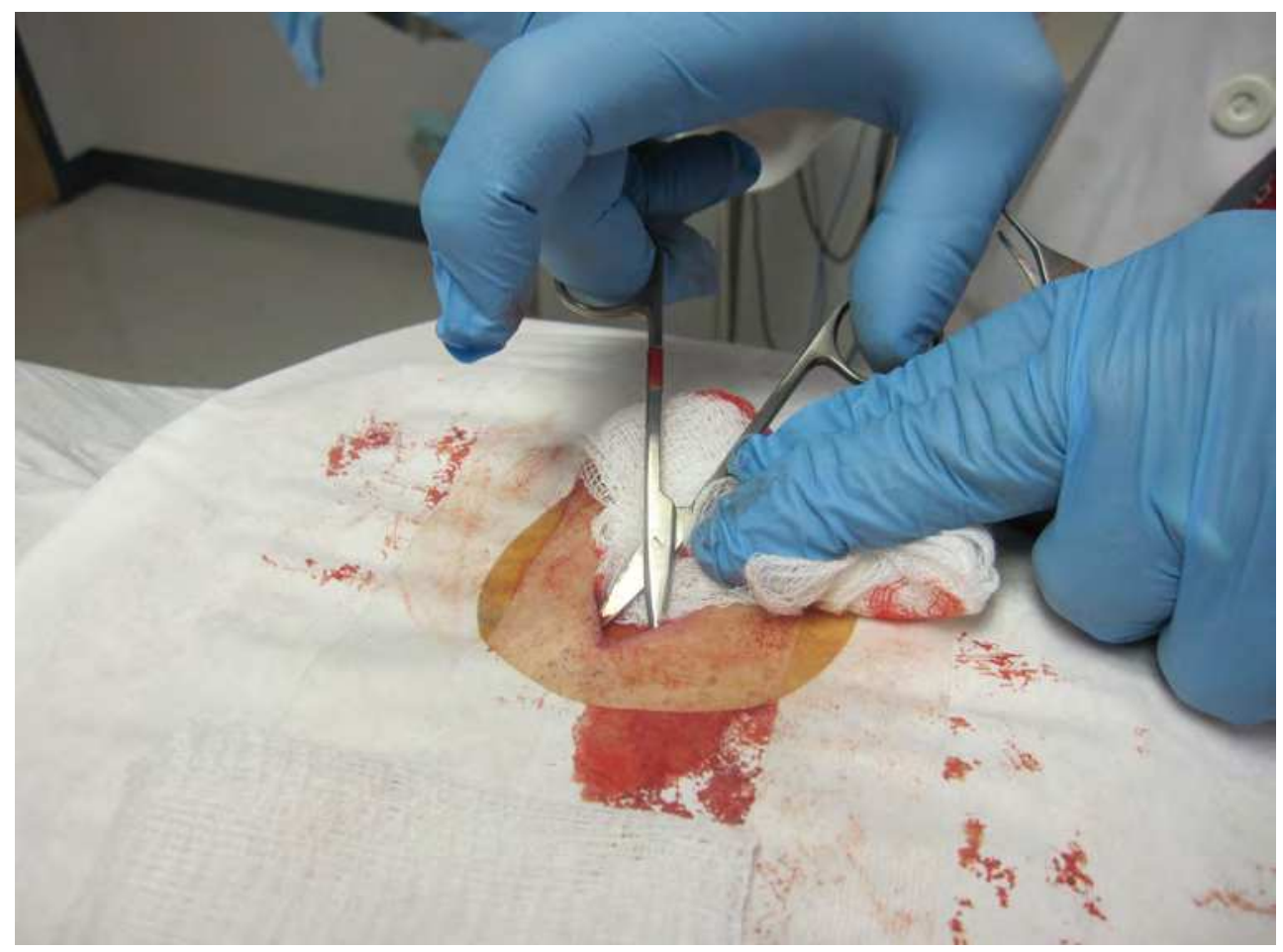

Fig. 11. Undermining the excision site prior to suturing

\section{Choice of suture and needle}

The qualities most important in suture are flexibility, strength, secure knotting, and infection potential.22 The two major categories of suture are absorbable and nonabsorbable. Absorbable suture is made from synthetic polymer or mammalian-derived collagen (gut). Common synthetic absorbables include polyglactic acid (Vicryl), polyglycolic acid (Dexon), and polydixanone (PDS). Absorbable sutures are usually placed deep in larger wounds to reduce skin tension for the final closure.

Nonabsorbable sutures are used for skin closure and permanent internal placement. Common nonabsorbable sutures include silk, nylon (Ethi-lon), and polypropylene (Prolene). Silk and nylon suture can be braided, adding strength and improving knotting potential, but are more likely to harbor infection. Polypropylene and unbraided nylon are monofilaments, and are less likely to harbor infection, but knots are less secure and more difficult to tie. Silk and gut, as natural materials, cause considerable tissue inflammation and have been largely replaced by synthetic suture material. 8,22

Generally, 4-0 or 5-0 monofilament nylon can be used on the body and scalp, and 6-0 nylon on the face.7, 16 Polypropylene can be considered for the scalp, primarily because it is blue and easy to see. 
Suture needles are made of noncorrosive stainless steel, especially forged to achieve maximum strength and ductility, the ability to bend under pressure without breaking.22 Suture needles have an eye, body, and point. Most needles have a swaged eye where the metal of the needle is molded around the end of the suture. This part of the needle is soft and likely to bend or break if mishandled. The body of the needle is designed for great strength and secure grasping; it is usually flattened with slight convex or concave sides to avoid rotation in the holder while suturing. Three types of needle points are common: cutting, tapered, and blunt. Cutting needles allow for easy passage through tough tissue and are ideal for skin. The size of the needle is ranked by a number, with higher numbers identifying larger needles. Needle curvature is measured in terms of proportion of a circle, with one-quarter, one-half, and three-eight curves available. When wound closing seems more difficult than expected, reassess the appropriateness of the instruments. Needle selection is often a prime factor in the ease of suturing and final cosmetic result. ${ }^{17}$

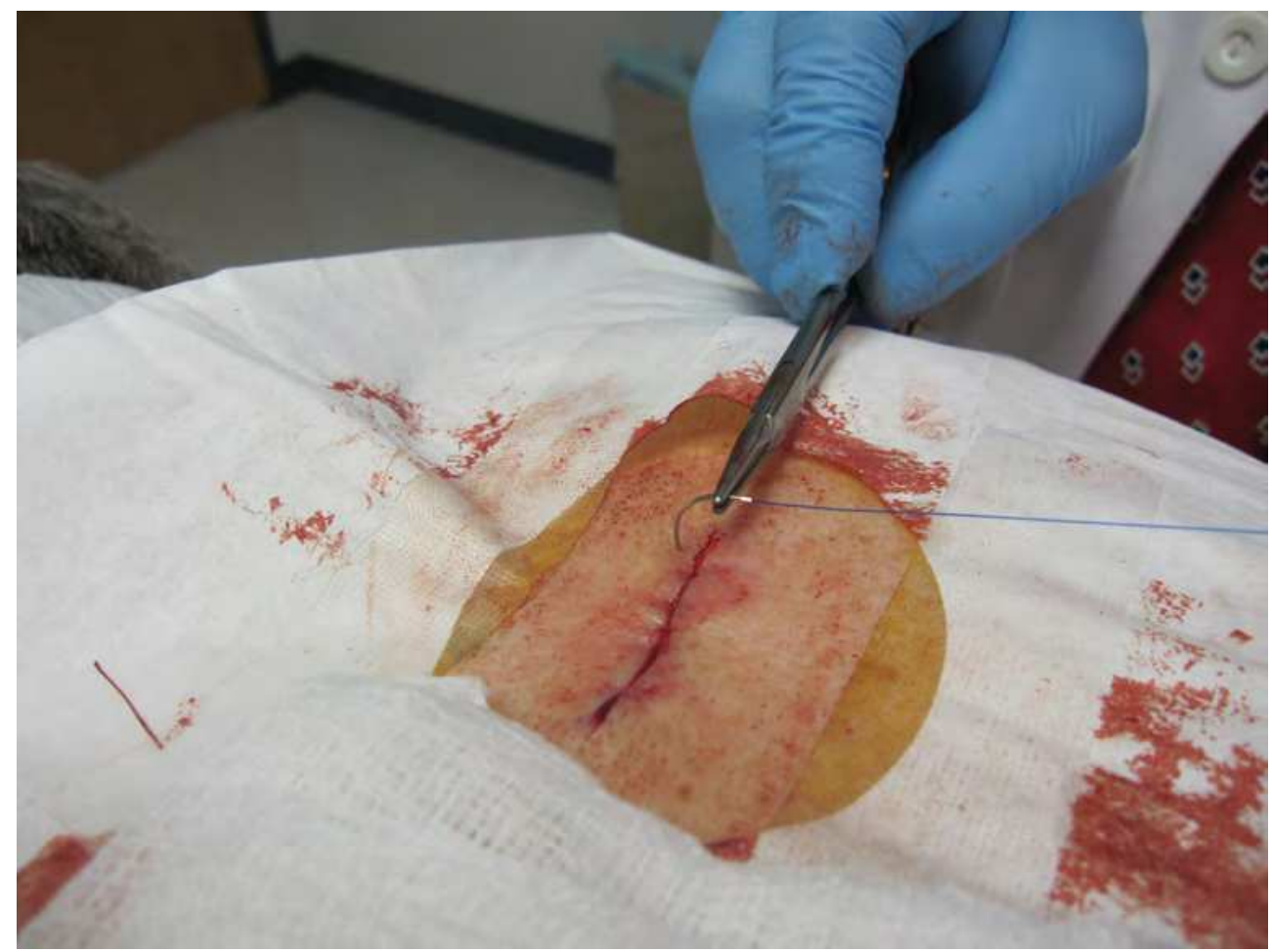

Fig. 12. Handling technique for suture needles

\section{Closing}

Primary closure of a punch wound can be accomplished with one or two, single-layer, interrupted sutures. Excisions can be closed in one or two layers, with two-layer closures giving better cosmetic results in the larger wounds. The most common closure technique is a simple, interrupted suture. ${ }^{7}$ To begin, grasp the needle with the needle-holder at midpoint or 
about one third the distance from the eye. (Fig. 12) This will provide maximum driving force and diminish the likelihood of bending or breaking the needle. A palm grip is recommended to increase the driving force of the needle through the skin. Place the handle of the holder in the palm, wrap the thumb and fingers around the handles, and extend the index finger down over the tip of the holder near the needle. The needle point is placed perpendicular to the skin surface about $2 \mathrm{~mm}$ away from the wound edge, and is driven down, then up into the center of the wound. A second insertion begins in the center of the wound, and exits the skin on the opposite side, $2 \mathrm{~mm}$ from the wound edge, perpendicular to the surface. If done properly, the suture will make a flask-shaped loop; the loop beneath the skin surface is farther apart than the entry and exit points on the surface. For small excisional wounds, and for most punch wounds, a needle exit in the middle of the wound is not necessary, but depends on the size of the needle and the ease that the wound edges can be approximated and everted.

The instrument tie is fast and efficient. To begin, hold the needle holder parallel to the long axis of the wound with the free end and needle end of the suture on either side of the holder. Wrap the needle end of the suture twice around the holder, then grasp the free end of the suture with the holder and pull through, tightening the knot. (Fig. 13) At this point the needle end and free end of the suture should have switched sides relative to the beginning. The process is repeated as needed, reversing the position of the free end and needle end of the suture with each knot. "Approximate, don't strangulate" acknowledges the importance of proper tension on the suture. Excessive tension can be recognized by blanching of the wound edges, and may indicate the need for subcutaneous sutures or simply less tension on each suture.

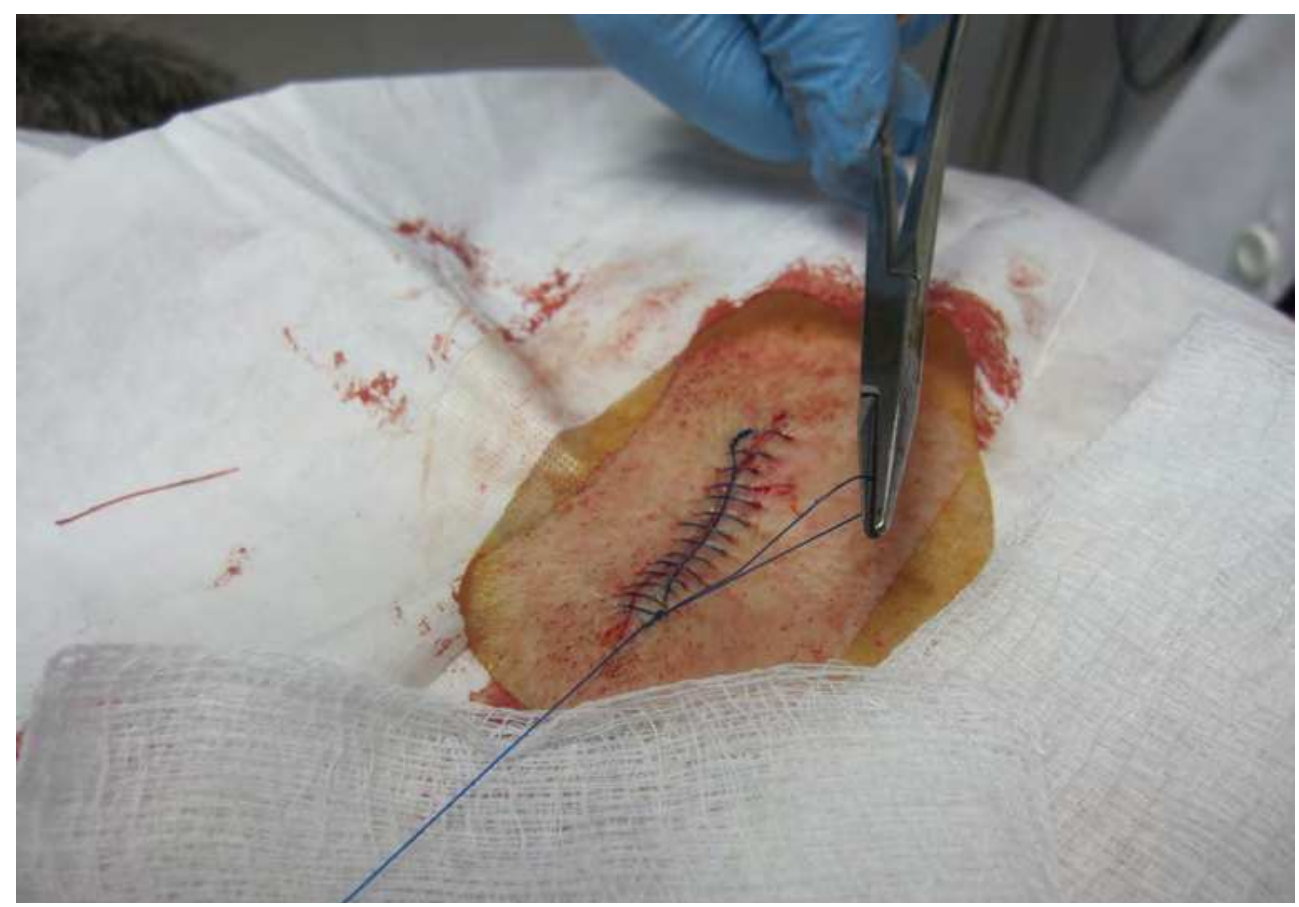

Fig. 13. Placement of sutures at excisional biopsy site 
Placement of sutures for elliptical excisions can be facilitated by following the "rule of halves." 7 The wound is divided in half by the initial suture placement, and each half is itself halved by the subsequent placement of sutures. Similar halving continues until all wound edges are approximated. Starting the initial suture at an apex rather than the middle runs the risk of "dog ears" at the opposite apex owing to the creation of uneven wound edges.

In large wounds, the skin tension can be reduced by placing a temporary initial suture at the midpoint of the wound, but farther from the edge than usual. At a later time, this suture can be removed as the wound is approximated with the permanent sutures. Diamond and hexagonal excisions are easily closed by placing the initial sutures at the two opposing points of the diamond or four opposing points of the hexagon, then adding other sutures as necessary to completely approximate the wound. The straight lines of the diamond and hexagon provide better approximation of edges for the beginner than do the curved surfaces of the ellipse. ${ }^{10}$

\section{Wound dressing}

Wounds heal faster when moist, and under an occlusive or semi occlusive dressing. All biopsy wounds can be dressed with a thin film of an antibiotic ointment (bacitracin, polysprin, mupirocin) or plain petrolatum to prevent crust formation, then covered with a Band-Aid or other nonadherent covering, and topped with a gauze dressing and tape.7, 23 The dressing should be removed in 12 to 24 hours and thereafter cleaned with soap and water twice daily. After cleaning, the wound should be covered with an antibiotic ointment or petrolatum. Wounds healing by secondary intention need to be redressed after each cleaning until healed over, or for at least 5 days, whereas this is optional for sutured wounds. For sutured wounds, showering is permitted after 24 hours, but use of hot tubs is prohibited until the sutures are removed. ${ }^{24}$

\section{Suture removal}

There is a balance between the tendency for wound dehiscence or stretching if the sutures are removed too early, and the production of suture marks if they remain too long. 8,22 Generally, sutures on the face can be removed in 3 to 5 days, followed by the application of semi permeable adhesive strips to reduce wound tension. Sutures on the chest, abdomen, arms, and scalp can be removed in 7 to 10 days, and those on the back and legs in 12 to 20 days.7, 22, 23 Physicians should remove sutures from their patients to learn first-hand the results of their suturing technique and wound healing. Any crust should be washed away with wet gauze, then the suture is gently lifted near the knot, and one side cut close to the skin surface. The suture is removed by pulling across the wound surface; pulling away from the wound puts tension on the wound and may cause dehiscence. ${ }^{7}$

\section{Complications}

The major complications include bleeding, infection, and allergic reactions. Most bleeding can be controlled with simple pressure on the wound.10 If this is not successful after 5 minutes, a single suture may be sufficient. If bleeding remains uncontrolled, remove the suture, find and tie off the bleeding vessel, then resuture. Bleeding and hematoma formation can be minimized by using a pressure dressing directly over the wound. Tape a folded $4 \times 4$ 
gauze pad tightly over the wound, or secure it with an elastic bandage or self-adhering wrap. An ice pack applied for 3 to 5 minutes several times during the first 24 hours will also help decrease bleeding, hematoma formation, pain, and edema. ${ }^{23}$

Infection, though relatively uncommon, is usually the result of Staphylococcus, Streptococcus, or Candida. If the wound is frankly purulent, or has an associated cellulitis, culture the discharge and begin oral antibiotics. Infected wounds in the hands, feet, and intertriginous areas are often infected with Candida and can respond to topical antifungal ointments. 25 Occasionally patients will develop reactions to topical antibiotics. ${ }^{26}$ The wound will be red, itchy, and may have vesicles. If this occurs, stop the antibiotic and apply a topical corticosteroid ointment. Tape reactions are usually irritant rather than allergic and improve simply by not taping, or sometimes by changing the direction of the tape on the skin. ${ }^{27}$

\section{Documentation}

All procedures must be documented in the medical record. Minimal content includes location and nature of the lesion, indications for procedure, what was done, and how it was performed, specimen disposition, and instructions to and follow-up plans for the patient. Documentation of location with diagrams, pictures and accurate measurements with a ruler using nearby anatomical landmarks as reference points should be done. This is especially important if there is the possibility of further excision at the original biopsy site in future. Often the original biopsy defect may heal so well as to completely conceal the original site. ${ }^{1}$

\section{Snip biopsy}

Snip biopsies are especially indicated for very superficial or pedunculated lesions such as acrochordons (skin tags), filliform warts, or seborrheic keratosis. The lesion is secured with a forceps and raised. This enables one to expose the base of the lesion and provide traction. A sharp scissors is then placed at the base of the lesion and it is cut (or snipped off). (Fig. 14)

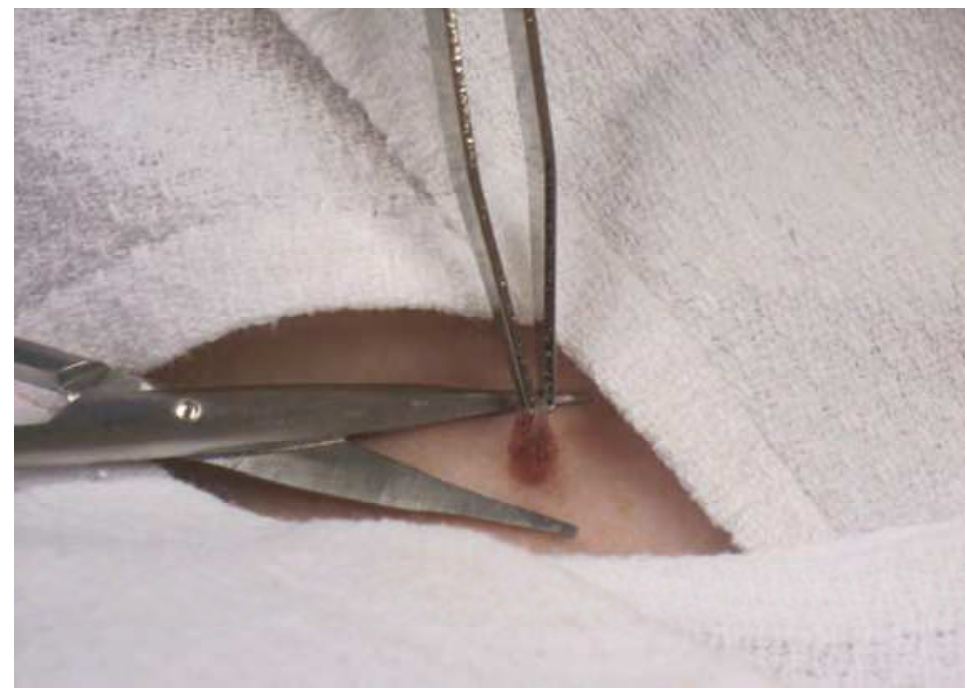

Fig. 14. Snip Biopsy 


\section{Incisional biopsies}

Incisional biopsies usually include a part of a lesion, or part of the affected skin plus part of the normal skin to show the interface between the two. These are usually performed for inflammatory processes involving the subcutaneous tissue or fascia, or well demarcated conditions where the specimen needs to include normal and abnormal skin. The location within the lesion should be chosen to include the most raised or pigmented part of the lesion. The depth of the incision is through the entire dermis down to the subcutaneous fat. Incisional biopsies have particular uses when the subcutaneous tissues must be examined (i.e., panniculitis, fibrous tumors).

Long and thin deep incisional biopsies are excellent on the lower extremities as they allow a large amount of tissue to be harvested with minimal tension on the surgical wound. Advantage of the incisional biopsy over the punch method is that hemostasis can be done more easily due to better visualization. 18

The technique of the incisional biopsy closely resembles that of the excisional biopsy. They are also a practical aid in planning definitive treatment of large lesions. The disadvantages of incisional biopsy include risk of bleeding and scarring, and limited tissue for histology in pigmented lesions, the incisional biopsy, like the punch biopsy, is only used where the excision is undesirable because of functional or cosmetic considerations. ${ }^{15}$

\section{Oral biopsies}

The same techniques that are used in the skin are also utilized in the oral cavity. Oral mucous membrane is histologically similar to the skin except for the absence of a stratum corneum. Hemostasis is difficult to achieve after the procedure because of the vascular nature of the oral cavity and limited access into an enclosed space. Special devices are used such as a Chalazion clamp greatly aids in performing these procedures. The physician should also be aware that oral biopsies may produce esthetic compromise as a result of scarring or residual deformity. The esthetic outcome is of particular concern when a lesion on the lip is near the vermilion border. ${ }^{28}$

\section{Pigmented lesions (Melanoma)}

An important caveat regarding removal of pigmented lesions is the possibility of malignant melanoma. The incidence of melanoma has almost tripled in the past three decades, growing faster than that of any other cancer. Because melanoma is notorious for its poor prognosis, accuracy and speed of diagnosis are essential. A high clinical suspicion for melanoma should be entertained for any pigmented lesion characterized by the ABCDs of malignant melanoma: asymmetry, /border irregularity, color variegation and (diameter more than $6 \mathrm{~mm}$, or rapid growth over a period of weeks to months. 16

Excisional biopsy can optimize the sampling of tissue suspicious for melanoma. The excision should be at the level of the subcutaneous tissue, where the Breslow depth of invasion and therefore the grade of melanoma can be determined. An elliptic or fusiform excision may span the entire breadth of the tissue, yet allow for good cosmetic results. ${ }^{29}$ Early diagnosis of melanoma has led to improved cure rates. In fact, approximately 50 percent of patients with melanoma present with lesions less than $1 \mathrm{~mm}$ in thickness, a thickness associated with a cure rate of 90 to 95 percent. ${ }^{30}$ Prompt referral is essential even after complete excision so further evaluation and therapy can be planned. Shave biopsy is never used for a pigmented 
lesion that may be melanoma. Shave biopsy of a malignant melanoma may destroy valuable information by transecting the lesion, making accurate measurement of depth and prognosis difficult. ${ }^{16}$ Punch biopsy should only be used with discretion for lesions suspicious for melanoma. Small lesions indicative of melanoma can be removed by a punch technique, provided that the lesion can be completely removed. In one study, only 32 percent of punch biopsies provided sufficient material for both definitive and complete evaluation of melanoma. Many of these biopsies were performed in lesions where suspicion of melanoma was minimal. ${ }^{30}$ However, the problem of sampling error is a critical factor in pathologic interpretation of pigmented nevi. The lack of invasive melanoma in one punch biopsy specimen within a large lesion does not prove the lack of cancer in another portion of the lesion. It is advisable to refer patients with large or awkwardly located suspicious lesions to dermatologist, rather than attempt a biopsy that may carry a high risk of either disfigurement or inadequate sampling.

\section{Summary}

Skin biopsy is an essential technique in the management of skin diseases. It can enhance dermatologic care but is not a substitute for clinical knowledge and decision making. Shave biopsy requires the least experience and time, but its use is limited to superficial lesions and should not be used for pigmented lesions. Punch biopsy is the primary diagnostic procedure in dermatology, is simple to perform, has few complications, and very small biopsies can heal without suturing. Although closing with sutures improves the cosmetic result, it requires more expertise and time. Excisions are ideal for removing large or deep lesions, provide abundant tissue for multiple studies, and can be curative for a number conditions including cancer. However, excisions require the greatest amount of expertise, time, and office resources, and are associated with more complications, including bleeding, infection and possibly scarring. Because of its complexity and complication potential, clinical training is highly recommended prior to attempting an excisional biopsy.7,9

\section{References}

[1] Patrick CA, Barbara MM. Skin Biopsy Techniques for the Internist. J Gen Intern Med. 1998 January; 13(1): 46-54.

[2] Fitzpatrick TB, Bernhard JD. The structure of skin lesions and fundamental of diagnosis. In: Fitzpatrick TB, Eisen AZ, Wolff K, Freedburg IM, Austen KF, editors. Dermatology in General Medicine. 3rd Ed. New York, NY: McGraw-Hill; 1987. p. 47. In. Ed.

[3] Pariser RJ. Skin biopsy: lesion selection and optimal technique. Mod Med. 1989; 57:82-90.

[4] Pinkus H. Skin biopsy: a field of interaction between clinician and pathologist. Cutis. 1977; 20:609-14.

[5] Peters MS, Winkelman RK. The biopsy. Dermatol Clin. 1984;2:209-17.

[6] Krull EA, Babel DE. Diagnostic procedures of the skin, part two: skin biopsy and other tests. J Fam Pract. 1976; 3:427-31.

[7] Dinehart SM, Hanke CW, Geronemus RG. Dermatologic Surgery for Medical Students. Schaumburg: Association of Academic Dermatologic Surgeons; 1993.

[8] Harrison PV. A guide to skin biopsies and excisions. Clin Exp Dermatol. 1980; 5:235-43. 
[9] Snell G. Skin biopsy. In: Pfenninger JL, Fowler GC, editors. Procedures for Primary Care Physicians. St. Louis, Mo: Mosby-Year Book; 1994. pp. 20-6. In: Eds.

[10] Grekin RC, Auletta MJ. Local anesthesia in dermatologic surgery. J Am Acad Dermatol 1988; 19:599- 614.

[11] Fewkes JL, Sober AJ. Skin biopsy: the four types and how best to do them. Primary Care and Cancer, 1993:13:35-9.

[12] Arca MJ, Bierman JS, Johnson TM, Chang AE. Biopsy techniques for skin, soft-tissue, and bone neoplasms. Surg Oncol Clin North Am. 1995; 4:157-74.

[13] Ritchie JM, Greene NM. Local anesthetics. In: Gilman AG, Rall TW, Nies AS, Taylor P, editors. The Pharmacological Basis of Therapeutics. 8th ed. New York, NY: Pergamon Press; 1990. pp. 311-31. In. eds.

[14] Bart RS, Kopf AW. Techniques of biopsy of cutaneous neoplasms. J Dermatol Surg Oncol. 1979; 5:979-87.

[15] Area M, Biermatin JS, Johnson TM, Chang AE. Biopsy techniques for skin, soft-tissue, and bone neoplasms. Surg Oncol Clin North Am 1995; 1:157- 74.

[16] Koh HK. Cutaneous melanoma. N Engl J Med 199I; 3Z'i: 17l-S2.

[17] Epperson WJ. Laceration and incision repair. In: Pfenninger JL, Fowler GC, editors. Procedures for Primary Care Physicians. St. Louis, Mo: Mosby-Year Book; 1994. pp. 711. In: eds.

[18] Achar S. Principles of skin biopsies for the family physician. Am Fam Physician. 1996 Dec; 54(8):2411-8.

[19] Olbricht, S. Biopsy Techniques and Basic Excisions. In: Dermatology, 1st edition,Bolognia, JL, Rapini, RP, et al (Eds), Mosby, London 2003. p.2269.

[20] Todd P, Garioch JJ, Humphreys S, Seywright M, Thompson J, du Vivier AWP. Evaluation of the 2-mm punch biopsy in dermatological diagnosis. Clin Exp Dermatol. 1996; 21:11-3.

[21] Grekin, RC. Simple dermatological surgical procedures. Res Staff Phys 1989; 35:61.

[22] Moy RL, Waldman B, Hein DW. A review of sutures and suturing technique. J Dermatol Surg Oncol. 1992; 18:785-95.

[23] Telfer NR, Moy RL. Wound care after office procedures. J Dermatol Surg Oncol. 1993; 19:722-31.

[24] Noe JM, Keller M. Can stitches get wet? Plast Reconstr Surg. 1988; 81:82-4.

[25] Bennett RG. Microbiological considerations in cutaneous surgery. In: Bennett RG, editor. Fundamentals of Cutaneous Surgery. St. Louis, Mo: CV Mosby Company; 1988. pp. 136-78. In: ed.

[26] Gette MT, Marks JG, Maloney ME. Frequency of postoperative allergic contact dermatitis to topical antibiotics. Arch Dermatol. 1992; 128:365-7.

[27] Grolnick M. Factors involved in the production of adhesive plaster irritation. Am J Surg. 1940; 50:63-78?

[28] Drore E. The Oral Mucosal Punch Biopsy. A Report of 140 Cases. Arch Dermatol. 1992; 128(6):815-817.

[29] Zuber TJ, Dewitt DE. The fusiform excision. Am Fam Physician 1994; 49:371-6,379-80.

[30] Devereux DF. Diagnosis and management of dysplastic nevus syndrome and early melanoma. Oncology 1990; 4:73-81. 


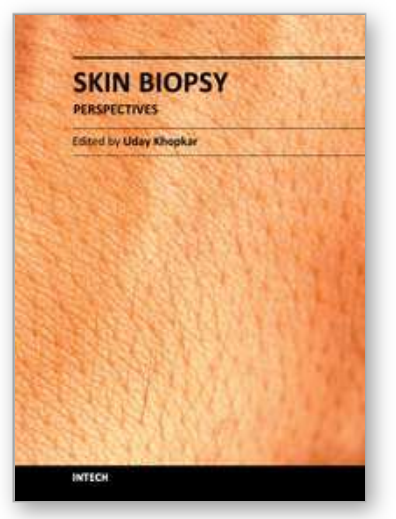

\author{
Skin Biopsy - Perspectives \\ Edited by Dr. Uday Khopkar
}

ISBN 978-953-307-290-6

Hard cover, 336 pages

Publisher InTech

Published online 02, November, 2011

Published in print edition November, 2011

Skin Biopsy - Perspectives is a comprehensive compilation of articles that relate to the technique and applications of skin biopsy in diagnosing skin diseases. While there have been numerous treatises to date on the interpretation or description of skin biopsy findings in various skin diseases, books dedicated entirely to perfecting the technique of skin biopsy have been few and far between. This book is an attempt to bridge this gap. Though the emphasis of this book is on use of this technique in skin diseases in humans, a few articles on skin biopsy in animals have been included to acquaint the reader to the interrelationship of various scientific disciplines. All aspects of the procedure of skin biopsy have been adequately dealt with so as to improve biopsy outcomes for patients, which is the ultimate goal of this work.

\title{
How to reference
}

In order to correctly reference this scholarly work, feel free to copy and paste the following:

Divey Manocha, Nidhi Bansal and Ramsay S. Farah (2011). Types and Selection Criteria for Various Skin Biopsy Procedures, Skin Biopsy - Perspectives, Dr. Uday Khopkar (Ed.), ISBN: 978-953-307-290-6, InTech, Available from: http://www.intechopen.com/books/skin-biopsy-perspectives/types-and-selection-criteria-forvarious-skin-biopsy-procedures

\section{INTECH}

open science | open minds

\section{InTech Europe}

University Campus STeP Ri Slavka Krautzeka 83/A 51000 Rijeka, Croatia Phone: +385 (51) 770447 Fax: +385 (51) 686166 www.intechopen.com

\section{InTech China}

Unit 405, Office Block, Hotel Equatorial Shanghai No.65, Yan An Road (West), Shanghai, 200040, China 中国上海市延安西路65号上海国际贵都大饭店办公楼405单元 Phone: +86-21-62489820

Fax: +86-21-62489821 
(C) 2011 The Author(s). Licensee IntechOpen. This is an open access article distributed under the terms of the Creative Commons Attribution 3.0 License, which permits unrestricted use, distribution, and reproduction in any medium, provided the original work is properly cited. 